\title{
More than a set of principles: analytical sociology at work
}

Carmelo Lombardo

\section{(2) OpenEdition}

\section{Journals}

Electronic version

URL: http://journals.openedition.org/ress/3004

DOI: $10.4000 /$ ress.3004

ISSN: 1663-4446

\section{Publisher}

Librairie Droz

\section{Printed version}

Date of publication: 15 May 2015

Number of pages: 293-301

ISSN: 0048-8046

\section{Electronic reference}

Carmelo Lombardo, "More than a set of principles: analytical sociology at work », Revue européenne des sciences sociales [Online], 53-1 | 2015, Online since 01 January 2019, connection on 23 April 2019 URL : http://journals.openedition.org/ress/3004; DOI : 10.4000/ress.3004 


\section{NOTE CRITIQUE}

\section{MORE THAN A SET OF PRINCIPLES: ANALYTICAL SOCIOLOGY AT WORK}

\section{Carmelo Lombardo (Sapienza University of Rome)}

Gianluca MANZO (ed.), 20I4, Analytical Sociology. Actions and Networks, Chichester, Wiley, p.xviii-430.

I. The movement known as analytical sociology (AS) has for years represented the most interesting challenge in the attempt to construct a so-called middle-range sociology such as that developed by Paul F. Lazarsfeld and Robert K. Merton at Columbia University in the I940's and 1950's'. Analytical sociology. Actions and Networks edited by Gianluca Manzo constitutes an interpretation of the identity of AS that is equally interesting. The aim that Manzo states in his introduction to this volume is a bold and ambitious one: to provide not only a better, clearer and more exhaustive list of the principles upon which the cognitive task of AS is based, but, above all, to give also a metatheoretical framework and a research program. This is of course my interpretation. The author keeps a low profile, presenting his position simply as a proposal for "a specific understanding of analytical sociology" which means neither "to speak for analytical sociology" nor to "polish and police its present boundaries", and the collected contributions as "a suite of variations on a common theme" (p.xiii). Rather than what AS currently represents, the focus is shifted on what AS could become (or wish to become) in the future. Such openness to the future is certainly the most interesting aspect of the author's entire proposal for an interpretation of AS, and is supported by a fruitful and promising exchange with "other theoretical and methodological approaches" (ibid.). As the author knows all too well, there is a double challenge in two realms: within AS itself, as it will imply a revision of theoretical and methodological principles that seemed well established; and in the exchange with other approaches, which might resist innovation or simply wish to defend and preserve their cognitive identity. This is, then, both a cognitive and social challenge, which concerns

I The expression "analytical sociology", introduced by Peter Hedström in Dissecting the Social. On the Principles of Analytical Sociology (2005), has entered the contemporary sociological lexicon. Its epistemological, theoretical, and methodological features were presented in Manzo (20l0), in Hedström and Bearman (2009b), and in the essays collected by Hedström and Bearman (2009a) as well as by Demeulenaere (20II). One can read a seminal collection of essays in Hedström and Swedberg (1998). Both conceptual clarifications and the main criticisms are presented in Manzo's introductory chapter. 
the contents of knowledge, the concrete way in which groups of researchers look at the research process, as well as the political and social relations between the researchers themselves. It is not only a set of principles and a research program as conceived by Imre Lakatos (I shall return to this point later), but also a proposal for a division of labor: the "accomplishment of this research program depends on a clear division of labor among quantitative and qualitative scholars, formal modelers, and experimentalists" (p.3). In order to achieve this, it is necessary that the "common theme" be clearly expressed.

2. I will then begin with the common theme: a specific interpretation of AS, which, first of all, requires an account of the route made since Peter Hedström's Dissecting the Social (2005), the movement's manifesto. As the author stresses, Hedström conceives AS as something which holds together a set of principles (on explanation, on the microfoundation of social phenomena, on the action theory, on interaction and interdependence processes, on the micro-macro transition, on the role of statistical methods and formal models for the empirical control of sociological theories), whose interdependence constitutes its most distinctive aspect in the scenario of today's sociology. It is this interdependence that produces a compound, in the chemical sense of the word, meaning a new intellectual substance-an emergent characteristic, as the analytical sociologists themselves would say. Manzo's work begins exactly from here, assuming this point as irreducible. But this is a starting point, not a conclusion, which "points to (one of) its possible future(s)" (p.3) without excluding any. However, starting from Dissecting the Social does not mean ignoring neither the collection of critical contributions and fruitful discussions that this book has produced, nor the diversity of theoretical and/or methodological options that many authors that can be counted among analytical sociologists have expressed with respect to the contents of some of the constitutive principles. Just to give one example: what characteristics should the logic of action have if the aim is to develop a generative model? Should it be calculation-based or ordinarybased or cognitive-based or ecological-based? As we will see, these are not mutually exclusive alternatives, but a possible continuum (see also Manzo, 20I2). We can then identify at least two aspects that the author will embrace in his interpretation of AS. The first is the heterogeneity of the theoretical and methodological positions, which are postulated as a value; the second is the attention to some of the critiques, conceived as guidelines to improve or extend the cognitive scope of the principles. Apart from the historical and conceptual misunderstandings of AS, taking the critiques put forward by many commentators seriously implies evaluating them cognitively one by one, and, in a way, codifying them. Thus, the openness to a (potential) cognitive conflict and especially to different styles of sociological work represents the reverse of any form of imperialism, which often operates in intellectual projects. Since the conflict between different styles of sociological work is mostly social in nature, as Merton pointed out in his studies in the sociology of knowledge (1973, esp. Chapter 3), a significant part 
of these critiques have particularly insisted on the lack of originality of AS, presenting it as a mere variation of theoretical and/or methodological options from the past. The interpretation that Manzo gives of AS corrects these misconceptions and gives value to the content of those critiques that allow for fruitful progress.

3. However, it is necessary to make one point clear. Although the author is aware of past debates and appreciates their most constructive and promising aspects, he proposes an interpretation of AS that wants to turn the page and start again. The challenge is to leave behind the epistemological and/or ontological discussions on the different interpretations of the concept of mechanism, of mechanism-based explanations, of action theory and of methodological individualism, in order to deal with each of these aspects in the actual research process. The most distinctive aspect of AS is the virtuous and progressive relation between theoretical elements and methodological instruments, knowing that the natural environment to develop this relation is the field of empirical research. The principles discussed by the author, then, represent "a set of research guidelines for both theoretical model building and empirical model testing in sociology" (p.7). The uniqueness of AS in the current sociological scenario consists precisely in the combination of these principles, and in the fact that they are put into work in parallel and jointly. The principles are seven, and are presented by Manzo in a sequence from $\mathrm{P}_{\mathrm{I}}$ to $\mathrm{P}_{7}$ : use clear and precise concepts, avoiding any linguistic obscurity $\left(\mathrm{P}_{\mathrm{I}}\right)$; describe facts using empirical information and suitable technical tools ( $\mathrm{P}_{2}$ ); formulate a generative model to explain the social outcome described $\left(\mathrm{P}_{3}\right)$; provide a description of the micro-level entities $\left(\mathrm{P}_{4} \mathrm{a}\right)$ and activities $\left(\mathrm{P}_{4} \mathrm{~b}\right)$ at work, and of the structural interdependencies $\left(\mathrm{P}_{4} \mathrm{c}\right)$ in which they operate; translate the generative model into an agent-based computational model $\left(\mathrm{P}_{5}\right)$; compare the computational model's outcomes with the empirical description of facts (P6); inject empirical experimental data into the agent-based computational model ( $\mathrm{P} 7)$. Although the discussion of each of the principles cannot be carried out individually and separately from the general discussion, the analysis of principles $\mathrm{P}_{3}$ (generative models), $\mathrm{P}_{4} \mathrm{~b}$ (logics of action), $\mathrm{P}_{4 \mathrm{C}}$ (structural interdependency) and $\mathrm{P}_{5}$ (agent-based modeling) is particularly interesting. These specific principles represent especially accurate codifications of theoretical achievements and empirical research results that can serve as a starting point. In a sense, these principles constitute the hard core of Manzo's proposal. Let us consider generative models $\left(\mathrm{P}_{3}\right)$. These concern the problem of a mechanism-based explanation, but this explanation is not based on the mechanisms themselves, but rather on models of mechanisms. While the first are elements from the social world, the latter are theoretical constructs that hypothesize the functioning of the mechanism itself (p.i7). Thus, according to AS explaining a social phenomenon means constructing a model that is capable of hypothesizing its generation, and thus testing it empirically. Since social agents are parts of the generative model, it is necessary to construct a map to codify the main prospectives relating to the rationality of action $\left(\mathrm{P}_{4} \mathrm{~b}\right)$, which are placed on a continuum 
"whose extremes are the calculation-based rationality $[. .$.$] and the 'ecological' rationality$ of the 'fast-and-frugal heuristic' research program” (p.22).

The distinctive criterion, however, is realism, meaning how much each of these perspectives converges, diverges or corresponds to the research results. Depending on the cognitive objectives, on the status of our theoretical knowledge and on the empirical results available, it can be reasonable to use a simple agent, as long as the types of reasons that can be employed in different situations are clearly identified, and cannot be identified a priori once and for all. Codifying the spectrum of reasons that realistically orient agents' actions opens up new perspectives for research, focusing on the aspects that can be further investigated both at the theoretical and empirical levels. This is the way to construct integrated models of behaviors that combine different mechanisms coming from different research traditions. These include perspectives developed within social and cognitive psychology, perspectives developed within cultural sociology, guidelines emerging from lab experiments on the reflective manner in which agents make decisions and solve complex problems "by creating cognitive shortcuts that prove useful in a given choice setting” (p.26). The latter, can be both slow, effortful, conscious processes, and fast, automatic, unconscious, and are selected depending on the type of scripts, rituals and codes that characterize the situational logic in which the action takes place.

Since agents' action takes shape within structural interdependences $\left(\mathrm{P}_{4} \mathrm{c}\right)$-i.e. it is simultaneously bound and made possible by the interrelation between institutional, cultural and contextual elements on the one hand, and genuinely relational elements on the other hand-it is necessary that the generative model includes hypotheses on the nature and the characteristics of the structural interdependences, in which the micro-level entities could be embedded. Thus, if individual desires and beliefs represent motives for action, local interactions, membership to specific social networks and the structural position occupied by the agent represent the means through which value- and/or culture-oriented behavior patterns are selected and concretely expressed. It appears clear, then, why actions and networks represent the two pillars of AS, and all contributions in the book consist in in-depth explorations of $\mathrm{P}_{4}$ in general, carried out through exemplary and creative research experiences. However, the central principle of the entire AS strategy in Manzo's interpretation is $\mathrm{P}_{5}$. Since it aims to check the connection between models of mechanisms and observed macro phenomena, this principle proposes the transformation of the generative model into a formal one of a computational type. Agent-based models represent the preferred methodological tool (at least for $\mathrm{Manzo}^{2}$ ) due to a sort of structural homology between the characteristics of the

2 Manzo (2014a) is also the editor of a monographic issue published by the Revue française de sociologie. In his introduction, he analyzes the main features of agent-based models, that make them useful for sociologists, particularly for the construction of mechanisms-based explanations, the transition micro-macro, and the relationship with empirical available data (see Manzo, 20 I4b). 
mechanisms in question (entities, properties, activities, interactions) and the characteristics of the computer basis of multi-agent systems (objects, attributes, functions, communication). Like mechanisms (the basic units of generative models), objects (the basic units of a multi-agent system) are conceptually empty, flexible, generative (their dynamic dimension allows, through algorithmic causality, to put to work the requirement of generativity that is so typical of mechanism-based explanations). Objects allow to determine the possible macroscopic consequences of hypothetical mechanisms, thus enabling new and promising perspectives concerning the micro-macro transition. They are powerful tools capable of combining simplicity and realism, theoretical imagination and rigorous empirical check, comparison between simulated and empirical data, and indirect (using qualitative observation) and direct (using quantitative information) empirical calibration. Essentially, multi-agent models represent a methodological tool to combine theoretical reflection and empirical data produced in different research areas (from lab and experimental studies to survey data and longitudinal or historical data) and quantitative and qualitative methods.

In addition to the chapters by Manzo and by Hedström and Ylikoski-the first more generic and ambitious, the latter more focused on the theoretical and methodological differences between AS and Rational Choice Theory, both representing a genuine systematization of the AS research program³ - the other I4 contributions in the book consist in variations on the common theme as well as proposals for theoretical and methodological integrations and/or explorations of new research problems. Within the logic of a research program, they represent exemplary cases of theoretically and empirically progressive problemshift, in Lakatos' sense. But unlike Lakatos' work, there is no priority for discovery or theoretical invention over empirical justification-which, in Lakatos' terms, can occur even a lng time after the formulation of a theoretical idea. Instead, theoretical and empirical progressiveness are postulated as serving as each other's basis, in a continuative, circular and mutually amplifying relation. In this sense, AS represents, also in Manzo's understanding, a form of middle-range sociology as conceived by Merton (see, on this point, Hedström and Udéhn, 2009).

4. The above set of principles is not "a set of universal normative imperatives" but "a set of logically organized guesses as to the fruitfulness of a specific list of theoretical and methodological options [...] within a given pieces of research" (p.9). In this sense, it is reminiscent of Lakatos' research program (1978). On the one hand, however, the methodology put forward by Lakatos' research programs was the result of a historical sequence of philosophies of science that were considered inadequate compared to the process of scientific knowledge-Justificationism, Neojustificationism (i.e. Probabilism), Conventionalism, Dogmatic falsificationism. It represented a sophisticated and methodologically sensible 
version of falsificationism (Lakatos, in fact, named it Methodological falsificationism), which maintained nonetheless a universal and normative aspect. On the other hand, the set of principles that characterize AS is not conceived as a priori methodological rules, from which to derive concrete research operations, but as idealized characterizations that originate in the research process itself, and that are founded on existing theoretical ideas and empirical studies. Unlike Lakatos' research program, on the epistemological level this represents a naturalistic version of the knowledge process (relating to the actual theoryoriented empirical research), rather than a rationalistic one. The reference to Lakatos' research program must thus be interpreted in a metaphorical (and perhaps intuitive) sense, as a way to deal with a specific substantive problem through an appropriate combination of theoretical ideas and research results. In a more abstract manner, it can also be interpreted as a sequence of developing theories, characterized a) by their hard core (negative heuristic), a set of principles that must never be questioned and that the scientist must protect from the modus tollens (i.e. the attempt to confute them) by "inventing" auxiliary hypotheses, which constitute a sort of protective belt around the hard core, toward which the modus tollens is moved; and b) by an agenda that sets out the substantive problems on which to focus and work (positive heuristic). In this last sense, the choice of anomalies and/or puzzles to be faced and solved is never random (Lakatos explicitly and polemically refers to Thomas Kuhn's concept of normal science), to the extent that it is possible to effectively think of a hierarchy of problems. Although used in a metaphorical sense, then, the reference to Lakatos' research program has the purpose of establishing a double function for the set of principles: they represent both the negative heuristic (the "hard core" of the program of AS) and the guidelines for an agenda of concrete problems (both theoretical and empirical) in a hierarchical order (the positive heuristic).

5. There is one last point, which I have already touched upon: the ambition of the project put forward in the book. Is this ambition excessive, as the author rhetorically asks in the final chapter? His answer, of course, is that it is not, and I fully agree with him. If the map presented by Manzo is convincing (and I believe it is), it represents a proposal for a transition to a new phase, not only for AS but also for "The Rest of Sociology". A research program, in the same way as the activity of normal science in Kuhn's sense, is possible only if it begins with a maturation of the field. Analytical Sociology. Actions and Networks proves that this is the case. But the epistemological reflection on the "process" of science has highlighted a close relation between general stances (world that AS represents the best research strategy for sociology. Instead, he supports a plurality and variety of research approaches for sociology, equally legitimate, and irreducibles to AS research program (on this point see also Bearman, 2012 and Santoro, 20I2). With reference to "The Rest of Sociology", for Lizardo (2012) AS research program lacks innovation and empirical progress, and represents a superfluous revolution. 
visions, conceptual frameworks, paradigms, research programs, reasoning styles and so on), the construction of theories, their transformation into methodological tools for data collection and analysis, and empirical research. Even a superficial glance at contemporary epistemology reveals not only the inevitability of these relations, but also that the social sciences, and most of all sociology, represent a privileged point of view on the concrete ways in which metatheoretical options function as a guide for theories and dynamic processes in research. Social sciences and sociology are indeed characterized not only by theoretical pluralism but also, and perhaps especially, by metatheoretical pluralism. Following Kuhn's The Structure of Scientific Revolutions (1970 [1969]), the pre-paradigmatic state of sociology has given birth to school of thoughts, with few channels of communication and even fewer conceptual and research interconnections. However, as Merton noted, the Kuhnian option of a dynamic process that has its final point in paradigmatic monism (1976, p.I3I) fails to detect the true status of sociology—and, in this respect, the reference at Lakatos' research program is convincing. Instead, a plurality of paradigms and of research programs might succeed in satisfying different functions in the evolution of a discipline. Merton identifies at least two of these functions: the first concerns the selection and conceptualization of a great variety of research problems; the second suggests that paradigms direct researchers to different types of phenomena that can be best used to analyze each succession of problems. If each of these paradigms/research programs is intellectually disciplined, pluralism and diversity will be instrumental to explore the different aspects of human actions and society, that a single paradigm might overlook. If the constellation of paradigms/research programs that has historically characterized sociology throughout its evolution has not represented a hindrance to the accumulation of sociological knowledge, it has however shifted the competition between paradigms from the cognitive to the social ground. Sociological paradigms/research programs, in the same way as scientific ones, are inextricable links of cognitive interests and networks of social relations, and the balance between the two levels is always precarious and never fully realized. Therefore, as Merton himself repeatedly demonstrated in his analyses of science, the competition between exponents of different paradigms/research programs has often concerned the allocation of resources or the recruitment of new generations of researches rather than cognitive confrontation.

But, as it has already been noted, the diversity of sociological styles, even those which share the metatheoretical idea that macro phenomena are the product of aggregated individual actions, tend to prioritize social over cognitive competition. If the ambition, then, is for AS to count as scientific innovation, the social characteristics of innovation processes cannot be neglected. If theoretical and empirical progressiveness in the AS research program will only be established in the near future, it will not be possible to separate it from the way in which this proposal for innovation will imply a relative advantage (i.e. if it is socially perceived as better than the meta-ideas it aims to replace), and if it will be compatible 
with the existing values and research practices in ample sectors of the discipline. All of the necessary conditions are already in place, but will they be enough? Will the plurality of meta-theoretical and theoretical approaches remain in the form of "disciplined eclecticism", as suggested many years ago by Merton (1976, p.I42), or will they evolve into a reasoned research program? If this happens, we will be able to think of a new founding pact for Good Sociology — a founding pact that includes AS and "The Rest of Sociology".

AN. This article is supported by the Grant Agency of Czech Republic, grant n. P404/I I/0949. I am thankful to the Institute of Sociological Studies in Prague and to Prof. Hynek Jeřábek for his hospitality.

\section{BIBLIOGRAPHY}

DEMEULENAERE P. (ed.), 20II, Analytical Sociology and Social Mechanisms, Cambridge, Cambridge University Press.

HEDSTRÖM P., 2005, Dissecting the Social. On the Principles of Analytical Sociology, Cambridge, Cambridge University Press.

-, BEARMAN P. (eds), 2009a, The Oxford Handbook of Analytical Sociology, Oxford, Oxford University Press.

-, BEARMAN P., 2009b, "What is Analytical Sociology All About?", in Hedström, Bearman (2009a), p.3-24.

-, SWEDBERG R. (eds), 1998, Social Mechanisms: An Analytical Approach to Social Theory, Cambridge, Cambridge University Press.

-, UDÉHN L., 2009, "Analytical Sociology and the Theories of the Middle Range", in Hedström, Bearman (2009a), p.25-47.

-, YLIKOSKI P., 2010, "Causal Mechanisms in the Social Sciences", Annual Review of Sociology, 36, p.49-67.

KUHN Th., 1970 (1969), The Structure of Scientific Revolutions, Chicago,

Chicago University Press, $2^{\mathrm{e}}$ ed. with Postscript.

LAKATOS I., 1978, "Falsification and the Methodology of Scientific Research

Programmes", in J. Worrall, G Currie (eds), Imre Lakatos. Philosophical Papers,

Volume I, The Methodology of Scientific Research Programmes, Cambridge, Cambridge University Press, p.8-101.

LITTLE D., 2012, "Analytical Sociology and the Rest of Sociology", Sociologica, I, p. I-47.

LIZARDO O., 2012, "Analytical Sociology's Superfluous Revolution", Sociologica, I, p. I II.

MANZO G., 2010, "Analytical Sociology and its Critics", European Journal of Sociology, 5I-I, p.129-170. 
-, 2012, "Reason-based Explanations and Analytical Sociology: a Rejoinder to Boudon", Revue européenne des sciences sociales, 50-2, p.35-65.

-, 2014a (ed), Revue française de Sociologie, "La simulation multi-agents: principes et applications aux phénomènes sociaux", 55-4.

-, 2014b, "Potentialités et limites de la simulation multi-agents: une introduction", in Manzo (2014a), p.653-688.

MERTON R.K., 1973, The Sociology of Science: Theoretical and Empirical Investigations, Chicago, Chicago University Press.

-, 1976, "Structural Analysis in Sociology", in Sociological Ambivalence and Other Essays, New York, The Free Press, p. I09-144.

SANTORO M., 2012, "The Whole and the Parts. Or: is Analytical Sociology Analytical Enough About Sociology, and Itself?", Sociologica, I, p.I-32. 